\title{
A case report of syndrome of inappropriate antidiuretic hormone secretion with Castleman's disease and lymphoma
}

\author{
Chong-Gui Zhu', Qiu-Zi Zhang ${ }^{1}$, Mei Zhu ${ }^{1 *}$, Qiong-Li Zhai ${ }^{2}$, Xiao-Yu Liang ${ }^{3}$, Zong-Hong Shao ${ }^{4}$, \\ Emily C Ver Hoeve ${ }^{5}$ and Hui-Qi Qu ${ }^{5}$
}

\begin{abstract}
Background: Syndrome of inappropriate antidiuretic hormone secretion (SIADH) is a common cause of hyponatremia in hospitalized patients and is often described in patients with small-cell carcinoma of the lung. In this report, we described both Castleman's disease and lymphoma coexisting in one patient with SIADH.

Case presentation: A 70-year-old Chinese woman with a history of diabetes mellitus and insulin therapy had severe hyponatremia and gastrointestinal symptoms. Through a series of examinations, common causes such as pulmonary carcinoma were excluded. An abdominal mass was detected by computed tomography. Although the peripheral lymph node biopsy showed the pathological result as Castleman's disease, the pathology of the abdominal lymph node revealed diffuse large B-cell lymphoma. After chemotherapy, the hyponatremia was treated during a period of follow-up.

Conclusion: This patient presented with the rare clinical condition of inappropriate antidiuretic hormone secretion alongside Castleman's disease and lymphoma. Asymptomatic hyponatremia may persist for some time suggesting that clinical physicians should pay attention to the mild cases of hyponatremia. We also hypothesized that Castleman's disease is a condition of pre-lymphoma with both having the ability to cause SIADH. The possibility of lymphoma as well as Castleman's disease triggering the development of SIADH should also be taken into consideration for conducting recurrent biopsies.
\end{abstract}

Keywords: Castleman's disease, Hyponatremia, Lymphoma, Syndrome of inappropriate antidiuretic hormone secretion (SIADH)

\section{Background}

The syndrome of inappropriate antidiuretic hormone secretion (SIADH) is caused by the excessive release of antidiuretic hormone (ADH, also known as vasopressin) from the posterior pituitary gland [1,2] and can cause hyponatremia in hospitalized patients with an incidence as high as $30 \%$ [3]. SIADH is generally seen in patients diagnosed with small-cell lung cancer (SCLC) which was first described by Schwartz et al. in two patients with lung cancer [4].

\footnotetext{
* Correspondence: meichuqin@yahoo.com.cn

'Department of Endocrinology, Tianjin Medical University General Hospital, No 154 Anshan Road, Heping District, Tianjin 300052, China

Full list of author information is available at the end of the article
}

SIADH is not difficult to diagnose in clinic. It can be secondary to a variety of disorders, such as medications, malignancies, surgery, and HIV infection or be idiopathic [1,2]. While SCLC is the primary malignancy causing SIADH, lymphoma can also induce this condition $[5,6]$. In this report, the diagnosis of Castleman's disease was established before we suspected SIADH was caused by a malignancy. After extensive examinations, we made the final diagnosis of diffuse large B-cell lymphoma. Chemotherapy treatment was recommended for the patient and significantly ameliorated the SIADH symptoms. 


\section{Case presentation}

In October 2011, a 70-year-old Han Chinese woman with Type 2 diabetes (T2D) was admitted to Department of Endocrinology at the Tianjin Medical University General Hospital for uncontrolled hyperglycemia. The patient had a history of T2D for 21 years and received continuous long-term insulin treatment with a dosage of about fifty units per day. On the seventh day after admission, the patient developed symptoms of nausea and vomiting accompanied by left leg radiating pain without diarrhea and fever. She did not present with headache, dizziness, disturbance of consciousness, melana or hematemesis. The medications used in the hospital are listed in Table 1. The patient had no recent history of using diuretic agents. Serum sodium levels decreased to $112 \mathrm{mmol} / \mathrm{l}$ and chloride levels to $81 \mathrm{mmol} / \mathrm{l}$ with an effective osmolality at $267 \mathrm{mOsm} / \mathrm{kg} . \mathrm{H}_{2} \mathrm{O}$ (normal range: $280-310 \mathrm{mOsm} / \mathrm{kg}$. $\mathrm{H}_{2} \mathrm{O}$ ). Urinary sodium increased to $85 \mathrm{mmol} / \mathrm{l}$ and chloride to $86 \mathrm{mmol} / \mathrm{l}$ with an osmolality of $257 \mathrm{mOsm} / \mathrm{kg}$. $\mathrm{H}_{2} \mathrm{O}$ indicating hypotonicity during normal dietary salt intake. She was clinically normovolemic with no signs of fluid retention. Her hepatic and renal functions were normal with a serum creatinine of 68 (normal range: 44-115) umol/L. Fractional sodium excretion was calculated as $1.56 \%$. Thyroid and adrenal function were measured with $\mathrm{ACTH}=59.8 \mathrm{pg} / \mathrm{mL}$ (normal range: 0-46), cortisol $=25.6 \mathrm{ug} / \mathrm{dL}$ (normal range: $5-25)$, 24 -hour cortisol in urine $=64.4 \mathrm{ug}($ normal range: $30-110)$, FT3 $=$ 3.04 $\mathrm{pmol} / \mathrm{L}$ (normal range: $3.5-6.5$ ), FT4 $=19.76 \mathrm{pmol} / \mathrm{L}$ (normal range: $11.5-23.5$ ), $\mathrm{TSH}=3.657 \mathrm{uIU} / \mathrm{mL}$ (normal range: $0.3-5.0$ ) and $\mathrm{rT} 3=1.76 \mathrm{nmol} / \mathrm{l}$ (normal range: 0.43-1.15). The magnetic resonance imaging (MRI) of her pituitary gland showed herniation of the suprasellar cistern. Based on the MRI result, our first diagnosis was hypopituitarism, which was treated with intravenous hydrocortisone at $50 \mathrm{mg} /$ day. Both the serum sodium and serum chloride increased from 112 to $116 \mathrm{mmol} / \mathrm{l}$ and from 81 to $84 \mathrm{mmol} / \mathrm{l}$, respectively, on the following day.

After further inquiry, the patient informed us of a past history of Mucosal-associated lymphoid tissue lymphoma (MALT) which had not received further treatment. We also discovered that she was last hospitalized on March 2011 for uncontrolled hyperglycemia without symptoms of nausea and vomiting. Nevertheless, hyponatremia had been noticed with serum sodium of $131 \mathrm{mmol} / \mathrm{L}$ and serum

Table 1 Medications used in the current hospitalization

\begin{tabular}{lll}
\hline Medicine & Dose & Times \\
\hline Voglibose & $0.3 \mathrm{mg}$ & 3 \\
Glimepiride & $4 \mathrm{mg}$ & Once in the morning \\
Glimepiride & $2 \mathrm{mg}$ & Once in the evening \\
Insulin Aspart 30 & $28 \mathrm{IU}$ & 2 \\
Irbesartan & $150 \mathrm{mg}$ & 1 \\
\hline
\end{tabular}

chloride of $95 \mathrm{mmol} / \mathrm{l}$. Urinary investigation showed increased levels of sodium $(90 \mathrm{mmol} / \mathrm{l})$ and chloride (83 mmol/l) without corresponding osmolality data. Her renal function was normal with a serum creatinine of 63 umol/L. This information led us to believe that SIADH caused the patient's hyponatremia. Three days after restricting fluid intake to $1000 \mathrm{ml} /$ day, the serum sodium rose to $128 \mathrm{mmol} / \mathrm{L}$ from $116 \mathrm{mmol} / \mathrm{L}$. Ten days later, the patient's serum sodium levels increased to $142 \mathrm{mmol} / \mathrm{l}$, and the symptoms of nausea and vomiting disappeared.

Since the patient had a past history of MALT, we performed a gastric endoscopy, which indicated the absence of lymphoma. Additionally, the serology result was negative for purified protein derivative (PPD), and the serum and urine protein electrophoresis were also negative for monoclonal gammopathy. Additional laboratory findings were listed in Table 2. A negative chest computed tomography (CT) scan excluded the possibility of SCLC as the cause of SIADH in this patient. However, we noticed that the patient had obvious pain in the left leg, abdominal distension, and skin itching on a clinical exam and further discovered that her abdomen circumference had increased significantly in the last six months. An abdominal CT scan showed that a mass measuring approximately $49 \mathrm{~mm} * 70 \mathrm{~mm} * 90 \mathrm{~mm}$ was located on front lumbar vertebra 1-4 and the surrounding abdominal aorta. A subsequent abdominal enhancement CT revealed that the mass might be lymphoma (Figure 1). As the pathological result was critical for her diagnosis, we conducted a left inguinal lymph node puncture showing no abnormal lymphocytes. Consequently, a whole left inguinal $(2 \times 1 \times$ $0.5 \mathrm{~cm})$ lymph node was resected. The pathological morphology revealed that the lymph node structure was replaced with substantial amounts of lymphoid tissue and fibrosis. Thus, the diagnosis of Castleman's disease was established according to the pathological exam (Figure 2A, B, C).

Although hyponatremia was corrected, her hemoglobulin levels decreased from $109 \mathrm{~g} / \mathrm{L}$ to $96 \mathrm{~g} / \mathrm{L}$. With her consent, we conducted a biopsy of the enlarged abdominal lymph node by using a celioscope. The pathological exam disclosed diffuse large B-cell lymphoma with an anaplastic subtype (Figure 3A, B).

After the diagnosis of lymphoma was established, the patient was transferred to the Department of Hematology for further treatment. For the etiology treatment of B-cell lymphoma, the chemotherapy of cyclophosphamide, hydroxydaunorubicin, oncovin and prednisone $(\mathrm{CHOP})$ with rituximab (a monoclonal antibody against the protein CD20) was administered. The patient's serum sodium level stabilized without fluid restriction.

\section{Discussion}

In this case, the hyponatremia had existed for a long time and failed to gain proper attention until serious 
Table 2 Laboratory findings in the current hospitalization

\begin{tabular}{|c|c|c|c|}
\hline Exam & Value & $\begin{array}{l}\text { Reference } \\
\text { range }\end{array}$ & Unit \\
\hline $\mathrm{HbA1c}$ & $10.50 \%$ & $4-6 \%$ & \\
\hline FBG & 12.5 & $3.9-6.1$ & $\mathrm{mmol} / \mathrm{L}$ \\
\hline 24-h proteinuria & 124.2 & $0-150$ & mg \\
\hline Blood urea nitrogen & 4 & $1.7-8.3$ & $\mathrm{mmo} / \mathrm{L}$ \\
\hline Serum uric acid & 144 & $140-414$ & $\mu \mathrm{mol} / \mathrm{L}$ \\
\hline Serum creatinine & 68 & $44-115$ & $\mu \mathrm{mol} / \mathrm{L}$ \\
\hline $\mathrm{Ccr}$ & 86.8 & $80-120$ & $\mathrm{ml} / \mathrm{min}$ \\
\hline $\mathrm{ACTH}$ & 59.8 & $0-46$ & $\mathrm{pg} / \mathrm{mL}$ \\
\hline Cortisol & 25.6 & $5-25$ & $\mu \mathrm{g} / \mathrm{dL}$ \\
\hline 24-hour cortisol in urine & 64.4 & $30-110$ & ug \\
\hline FT3 & 3.04 & $3.5-6.5$ & $\mathrm{pmol} / \mathrm{L}$ \\
\hline FT4 & 19.76 & $11.5-23.5$ & $\mathrm{pmol} / \mathrm{L}$ \\
\hline TSH & 3.657 & $0.3-5.0$ & $\mu \mathrm{lU} / \mathrm{mL}$ \\
\hline rT3 & 1.76 & $0.43-1.15$ & $\mathrm{nmol} / \mathrm{l}$ \\
\hline ESR & 21 & $0-20$ & $\mathrm{~mm} / \mathrm{h}$ \\
\hline Lactic acid dehydrogenase & 186 & $94-250$ & $U / L$ \\
\hline B2-microglobulin & 2.04 & $0.8-2.0$ & $\mathrm{mg} / \mathrm{L}$ \\
\hline Antinuclear antibody & Negative & & \\
\hline Immunoglobulin G & 811 & $751-1560$ & $\mathrm{mg} / \mathrm{dl}$ \\
\hline Immunoglobulin A & 64.8 & $82-453$ & $\mathrm{mg} / \mathrm{dl}$ \\
\hline Immunoglobulin M & 48.1 & $46-304$ & $\mathrm{mg} / \mathrm{dl}$ \\
\hline C3 & 88.9 & $79-152$ & $\mathrm{mg} / \mathrm{dl}$ \\
\hline C4 & 17.10 & $16-38$ & $\mathrm{mg} / \mathrm{dl}$ \\
\hline C-reactive protein & 1.07 & $<0.80$ & $\mathrm{mg} / \mathrm{dl}$ \\
\hline Circulating immunologic complex & 4.2 & $<13$ & $\mathrm{U} / \mathrm{ml}$ \\
\hline Immunoglobulin E & $<5.00$ & $<165$ & $\mathrm{IU} / \mathrm{ml}$ \\
\hline Alpha Fetoprotein & 4.42 & $0-20$ & $\mathrm{ng} / \mathrm{ml}$ \\
\hline Ferritin & 272.87 & 4.6-204 & $\mathrm{ng} / \mathrm{ml}$ \\
\hline Carcinoembryonic antigen & 1.42 & $0-5$ & $\mathrm{ng} / \mathrm{ml}$ \\
\hline Carbohydrate antigen19-9 & $<0.60$ & $0-37$ & $\mathrm{U} / \mathrm{ml}$ \\
\hline Carbohydrate antigen 242 & 0.05 & $0-20$ & $\mathrm{U} / \mathrm{ml}$ \\
\hline Carbohydrate antigen 153 & 16.3 & $0-30$ & $\mathrm{U} / \mathrm{ml}$ \\
\hline HIV & Negative & & \\
\hline
\end{tabular}

clinical manifestations developed. Her past history of MALT as well as the success of fluid restriction and failure of hydrocortisone infusion suggested the possibility of hyponatremia caused by SIADH. One limitation of our investigation was the failure to measure urine uric acid and urea levels. Fractional uric acid excretion (FE-UA) has been demonstrated as a useful criterion in the diagnosis of SIADH particularly when attempting to differentiate between SIADH and hypovolaemic hyponatremia [7].

The main therapeutic issue in SIADH is fluid excess, and hyponatremia is dilutional in essence. Fluid restriction

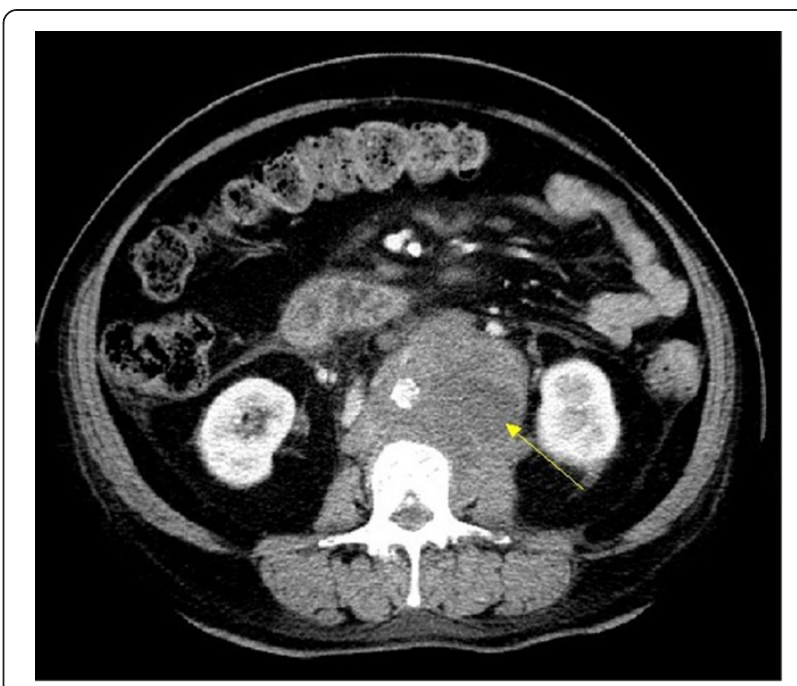

Figure $1 \mathrm{CT}$ scan of abdomen showing a mass. Axial contrastenhanced CT image shows a large lobulated irregular mass with inhomogenous enhancement that is encasing and anteriorly displacing the abdominal aorta.

is the primary treatment option for SIADH. The vasopressin V2 receptor antagonist is effective for assisting the SIADH treatment [8]. Urea administration could be used in patients with chronic SIADH but also in acute SIADH like in critically ill patients [9].

Once a diagnosis of SIADH is established, determining its cause is most important. Castleman's disease is characterized by non-cancerous growths that may develop in the lymph node tissue throughout the body [10]. Lesions often occur in the chest, abdomen, or neck, where the abnormal enlargement of lymph nodes could usually be found. Although SIADH is reported to be associated with Castleman's disease [11], the possibility of general lymphoma in this case could not be excluded. Several major points supported this conclusion including: (1) past history of MALT; (2) occurrence of itching (characteristic symptom of lymphoma); (3) CT scan findings suggested lymphoma; and (4) the manifestation of progressive anemia. Moreover, the patient had a long history of T2D treated with insulin. Recent studies suggest that insulin treatment may be associated with an higher risk of the developing certain types cancers including lymphoma [12].

Although Castleman's disease is inherently a nonneoplastic process, an association with concurrent or subsequent lymphoma has been well described [13]. The hyaline-vascular type of Castleman's disease which contains numerous lymphoid follicles should be differentiated from Hodgkin lymphoma and low-grade B-cell lymphomas [14]. Several B-cell lymphomas with prominent atrophic germinal centers and hyaline vascular penetration including follicular lymphoma, mantle cell lymphoma, and 


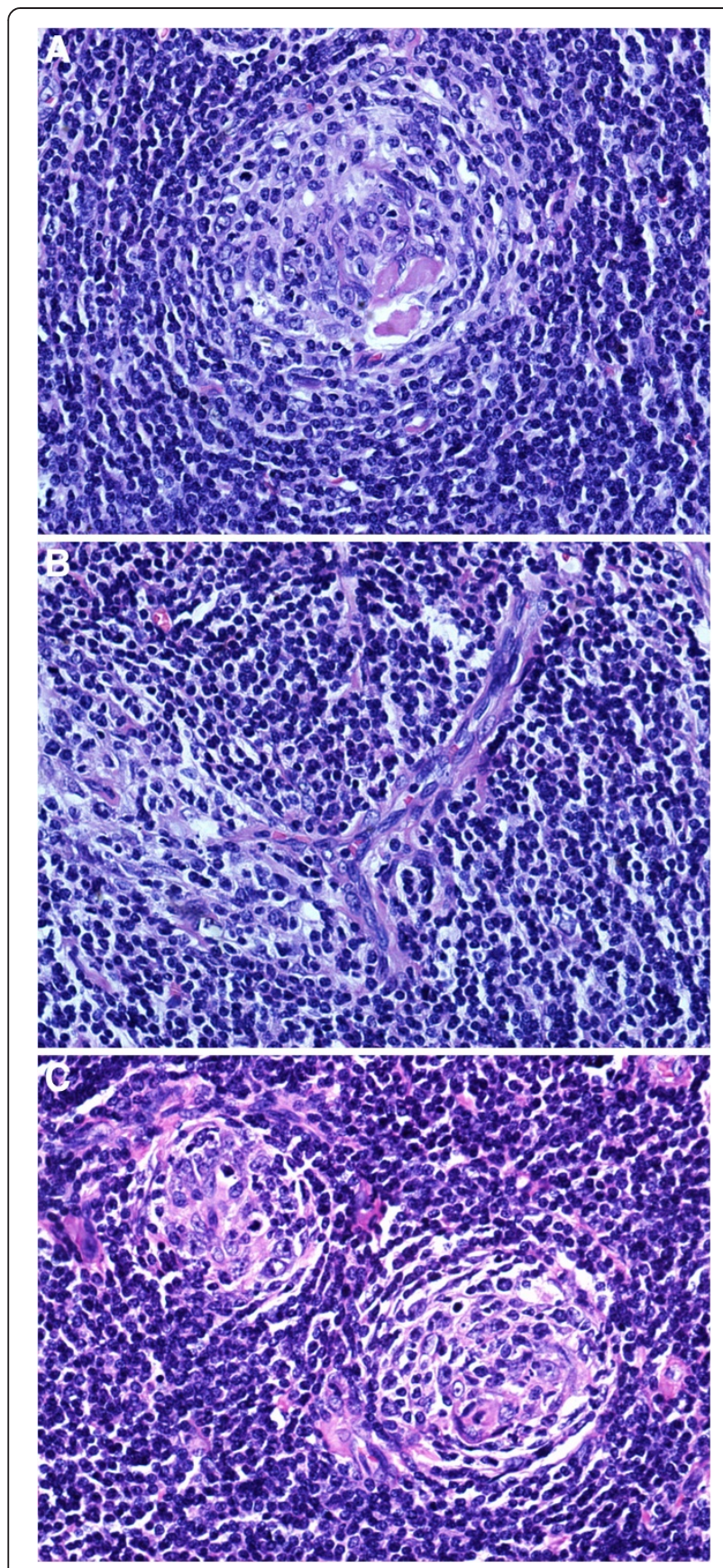

Figure 2 The pathological exam suggests Castleman's disease.

The gross examination of the inguenal lymph node biopsy

specimen shows a fairly well-encapsulated, soft tan lesion with a largest dimension of $1.2 \mathrm{~cm}$. Microscopy reveals areas of hyalinevascular Castleman's disease-like pattern. The majority of the lymphoid follicles had atrophic or regressive germinal centers, and some of them are penetrated by capillaries. There was concentric layering of lymphocytes in an onion-skin appearance and one or more penetrating blood vessels. The interfollicular stroma was also prominent with numerous hyperplastic vessels of the post-capillary venule type and plump endothelial lining. (A) concentric layering of lymphocytes in an onion-skin appearance; (B) a "lollipop" appearance; (C) two atrophic germinal centers within a single mantle zone.
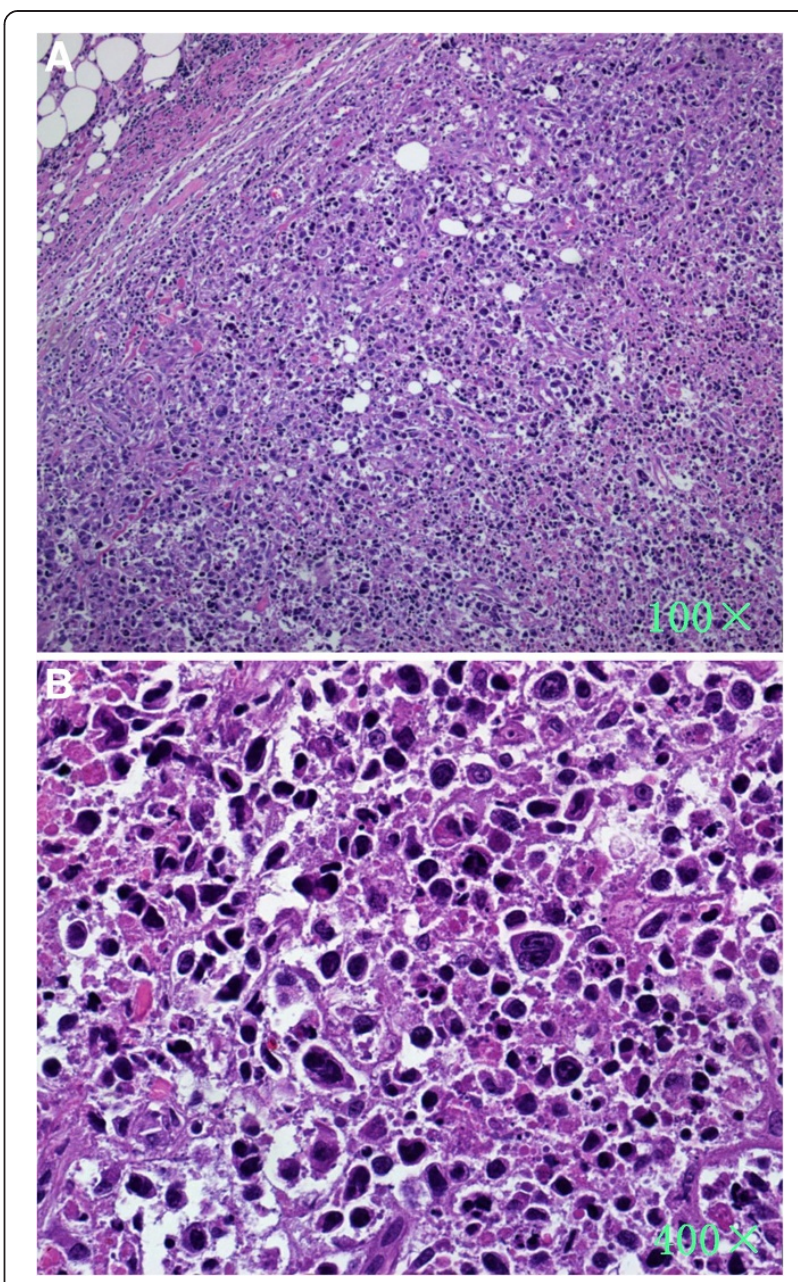

Figure 3 An abdominal lymph node biopsy suggests the diagnosis of diffuse large-B cell lymphoma, anaplastic subtype.

(A) At low magnification, the normal nodal architecture was totally effaced and the node was diffusely infiltrated by a population of large atypical lymphocytes with a highly characteristic morphology. Extensive infiltration of the perinodal adipose tissue was observed as well. (Haematoxylin and eosin). (B) High magnification show that nuclei were round to oval with fine chromatin; Extensive areas of coagulative necrosis and karyorrhectic nuclei were present. ReedSternberg-like forms and giant cells are also prominent and conspicuous nucleoli are seen in these cells. Eosinophilic region was seen near the nucleus, probably representing a prominent

Golgi apparatus.

nodal marginal zone lymphoma tend to be misdiagnosed as Castleman's disease due to the similar clinicopathologic features [15]. Furthermore, multicentric Castleman's disease could show similar FDG PET/CT appearance mimicking lymphoma, which reveals that Castleman's disease and lymphoma exhibit similar functions [16]. After consulting the literaure and examining the presentation of SIADH caused by both diseases, we hypothesized that Castleman's disease can develop into lymphoma, and a variety of pathological lymphomas may result in the 
development of SIADH $[6,17]$. One possible mechanism is the effect of hypercytokinemia. Some cytokines, such as interleukin (IL)-2, IL-6, IL-1 $\beta$, and tumor necrosis factor (TNF)- $\alpha$, have been reported to stimulate parvicellular and magnocellular neurons to secrete more ADH thus causing SIADH $[18,19]$.

In our case, three separate biopsies showed differing results suggesting that this procedure is so imperative for certain conditions that several biopsies may be needed for a final diagnosis.

\section{Conclusion}

This report describes a rare case, in which an older woman had both Castleman's disease and lymphoma coexisting with SIADH. We wish to highlight the following key points: First, lymphoma as well as Castleman's disease, though uncommon, is an important cause of SIADH, and mild hyponatemia should get proper attention by clinical endocrinologists. Second, repeated lymph node biopsy may be crucial for the etiological diagnosis of SIADH.

\section{Consent}

Written informed consent was obtained from the patient for publication of this case report and the accompanying images. A copy of the written consent is available upon request for review by the Journal Editor.

\section{Abbreviations \\ SIADH: Syndrome of inappropriate antidiuretic hormone secretion; ADH: Antidiuretic hormone; ACTH: Adreno-corticotrophic hormone; IL: Interleukin.}

\section{Competing interests}

The authors declare that they have no competing interests.

\section{Authors' contributions}

$M Z$ and CGZ led the conception and design, acquisition of data, review of literature, and drafted the manuscript. ZHS reviewed the manuscript. HQQ contributed the concept of research paper and critically reviewed the manuscript. QLZ expatiated the pathology and provided the pictures. All authors read and approved the manuscript.

\section{Authors' information}

$\mathrm{MZ}$ is the director of the Department of Endocrinology, Tianjin Medical University General Hospital. CGZ is the resident of Department of Endocrinology. HQQ is an Assistant Professor, Division of Epidemiology, Human Genetics and Environmental Sciences at School of Public Health, University of Texas Health Science Center at Houston.

\footnotetext{
Author details

${ }^{1}$ Department of Endocrinology, Tianjin Medical University General Hospital, No 154 Anshan Road, Heping District, Tianjin 300052, China. ²Department of Pathology, Tianjin Medical University Cancer Hospital, Huan-Hu-Xi Road, Tiyuanbei, Hexin District, Tianjin 300060, China. ${ }^{3}$ Department of Surgery, Tianjin Medical University General Hospital, No 154 Anshan Road, Heping District, Tianjin 300052, China. ${ }^{4}$ Department of Hematology, Tianjin Medical University General Hospital, No 154 Anshan Road, Heping District, Tianjin 300052, China. ${ }^{5}$ Division of Epidemiology, Human Genetics and Environmental Sciences, University of Texas School of Public Health, 1200 Herman Pressler, Houston, Texas 77030, USA.
}

Received: 4 October 2012 Accepted: 29 May 2013

Published: 4 June 2013

\section{References}

1. Pillai BP, Unnikrishnan AG, Pavithran PV: Syndrome of inappropriate antidiuretic hormone secretion: Revisiting a classical endocrine disorder. Indian J Endocrinol Metab 2011, 15(Suppl 3):S208-S215.

2. Esposito P, Piotti G, Bianzina S, Malul Y, Dal Canton A: The syndrome of inappropriate antidiuresis: pathophysiology, clinical management and new therapeutic options. Nephron Clin Pract 2011, 119(1):c62-c73. discussion $\mathrm{C} 73$.

3. Upadhyay A, Jaber BL, Madias NE: Incidence and prevalence of hyponatremia. Am J Med 2006, 119(7 Suppl 1):S30-S35.

4. Schwartz WB, Bennett W, Curelop S, Bartter FC: A syndrome of renal sodium loss and hyponatremia probably resulting from inappropriate secretion of antidiuretic hormone. J Am Soc Nephrol 1957, 12(12):2860-2870.

5. Morimoto K, Ogihara T, Shiomi T, Awaya N: Intravascular large B-cell lymphoma with preceding syndrome of inappropriate secretion of antidiuretic hormone. Intern Med 2007, 46(18):1569-1572.

6. Kobayashi K, Yokote T, Akioka T, Takubo T, Tsuji M, Hanafusa T: Inappropriate antidiuretic hormone production in diffuse large B-cell lymphoma. Br J Haematol 2008, 143(1):2.

7. Fenske W, Stork S, Koschker AC, Blechschmidt A, Lorenz D, Wortmann S, Allolio B: Value of fractional uric acid excretion in differential diagnosis of hyponatremic patients on diuretics. J Clin Endocrinol Metab 2008, 93(8):2991-2997.

8. Schrier RW, Gross P, Gheorghiade M, Berl T, Verbalis JG, Czerwiec FS, Orlandi C: Tolvaptan, a selective oral vasopressin V2-receptor antagonist, for hyponatremia. N Engl J Med 2006, 355(20):2099-2112.

9. Coussement J, Danguy C, Zouaoui-Boudjeltia K, Defrance P, Bankir L, Biston P, Piagnerelli M: Treatment of the syndrome of inappropriate secretion of antidiuretic hormone with urea in critically ill patients. Am J Nephrol 2012, 35(3):265-270.

10. Roca B: Castleman's disease: a condition with protean manifestations. Onkologie 2011, 34(8-9):412-414.

11. Galmarini O, Garrido CM, Felgueres M, Saccoliti M, Duran M, Sanchez B: Giant lymph node hyperplasia (Castleman's disease) with peripheral nerve diseases and syndrome of inappropriate secretion of antidiuretic hormone. Medicina (B Aires) 1987, 47(1):75-79.

12. Janghorbani M, Dehghani M, Salehi-Marzijarani M: Systematic Review and Metaanalysis of Insulin Therapy and Risk of Cancer. Horm Cancer 2012, 3(4):137-146.

13. Larroche C, Cacoub P, Soulier J, Oksenhendler E, Clauvel JP, Piette JC, Raphael M: Castleman's disease and lymphoma: report of eight cases in HIVnegative patients and literature review. Am J Hematol 2002, 69(2):119-126.

14. Kojima M, Shimizu K, Ikota H, Ohno Y, Motoori T, Itoh H, Masawa N, Nakamura S: "Follicular variant" of hyaline-vascular type of Castleman's disease: histopathological and immunohistochemical study of 11 cases. J Clin Exp Hematop 2008, 48(2):39-45.

15. Siddiqi IN, Brynes RK, Wang E: B-cell lymphoma with hyaline vascular Castleman disease-like features: a clinicopathologic study. Am J Clin Pathol 2011, 135(6):901-914.

16. Elboga U, Narin Y, Urhan M, Sahin E: FDG PET/CT appearance of multicentric Castleman's disease mimicking lymphoma. Rev Esp Med NuCl Imagen Mol 2012, 31(3):142-144.

17. Onishi C, Ikejiri F, Kawakami K, Miyake T, Kumanomido S, Inoue M, Takahashi T, Tanaka J, Yamamoto M, Sugimoto T, et al: Asian variant of intravascular large $B$ cell lymphoma causes patients to frequently develop the syndrome of inappropriate antidiuretic hormone secretion. Ann Hematol 2011, 90(11):1293-1297.

18. Lim GW, Lee M, Kim HS, Hong YM, Sohn S: Hyponatremia and syndrome of inappropriate antidiuretic hormone secretion in kawasaki disease. Korean Circ J 2010, 40(10):507-513.

19. Mastorakos G, Weber JS, Magiakou MA, Gunn H, Chrousos GP: Hypothalamic-pituitary-adrenal axis activation and stimulation of systemic vasopressin secretion by recombinant interleukin- 6 in humans: potential implications for the syndrome of inappropriate vasopressin secretion. J Clin Endocrinol Metab 1994, 79(4):934-939.

doi:10.1186/1472-6823-13-19

Cite this article as: Zhu et al:: A case report of syndrome of inappropriate antidiuretic hormone secretion with Castleman's disease and lymphoma. BMC Endocrine Disorders 2013 13:19. 